\title{
Performance of Different Breeding Methods in Cowpea (Vigna unguiculata (L). Walp) Improvement Programmes
}

\author{
S. de Z. Abeysiriwardena ${ }^{2}$ \\ Postgraduate Institute of Agriculture \\ University of Peradeniya \\ Sri Lanka
}

M.C. Millawithanachchi, V.A. Sumanasinghe ${ }^{1 *}$, A.P. Bentota ${ }^{1}$ and

\begin{abstract}
Effectiveness of different breeding methods in crop improvement is important to the breeders of a particular crop. .Hence, the effectiveness of three breeding methods namely, pedigree, single seed descent and modified bulk were evaluated using two cowpea [Vigna unguiculata (L) Walp] crosses CP $19 \times$ Waruni and CP $20 \times C P$ 22, at the Grain Legumes and Oil Crops Research and Development Center at Angunakolapellessa in Sri Lanka. All three breeding methods were imposed from the F2 populations of two cowpea crosses during 2011 Yala season and F3, F4 and F5 populations for each method were established during 2012/12 Maha, 2012 Yala and 2012/13 Maha seasons, respectively. The ten best lines from each method were selected at F5 generation and advanced to F6 generation. The selected 30 lines from the three breeding methods, two parents and three standard checks were tested for each cross in a Randomized Complete Block Design during 2013 Yala season. Data were recorded on plant height at maturity, number of peduncles per plant, number of pods per plant, number of seeds per pod, average length of pod, hundred seed weight and yield per plant in F4, F5 and F6 generations. Lines/methods were found to be significant $(p<0.05)$ for all the characteristics studied at F6 generation, except the number of pods per plant and pod length in CP $19 x$ Waruni and seed per pod in CP $20 x C P$ 22. The mean sum of squares of days to maturity in CP $19 x$ Waruni and seed per pod in both crosses were found to be significantly different among three breeding methods but for other characteristics, methods were found to be not significantly different $(p<0.05)$. The pods per plant and hundred seed weight recorded attractive narrow sense heritability values and significant intergeneration correlations. Positive phenotypic correlations were recorded between the seed yield and pods per plant in F4, F5 and F6 generations. Accordingly, in cowpea improvement, comparable results could be obtained among pedigree, single seed descent and modified bulk methods. In addition, indirect selection for higher number of pods per plant and hundred seed weight could increase seed yield.
\end{abstract}

Keywords: Breeding methods, cowpea improvement, correlation, heritability

\section{INTRODUCTION}

Cowpea [Vigna unguicula (L). Walp] is an integral crop component of rain fed Dry Zone farming systems of Sri Lanka. Its characteristic ability to grow under marginal conditions while providing a considerable amount of yield has encouraged resource poor farmers in the

\footnotetext{
1 Depertment of Agricultural Biology, Faculty of Agriculture, University of Peradeniya, Sri Lanka

2 CIC-seed farm, Pelwehera, Dambulla

* Corresponding author: sajanas@pdn.ac.lk
} 
Dry Zone to cultivate cowpea as a major crop in their crop land. Though the yield of improved cowpea varieties reaches $1.6-1.8$ t/ha under research conditions, the national average yield still remains at $1.18 \mathrm{t} / \mathrm{ha}$ (Department of Agriculture, 2010). Unavailability of good quality seeds, lack of knowledge on new varieties, uncertainty of rainfall, occurrence of pests and diseases, poor attention of farmers and unavailability of suitable varieties for rain fed conditions are the major constraints encountered by farmers, which lead to poor yields (Jayamanne, 1989).

Identification of drawbacks of the recommended varieties and the actual breeding requirement of cowpea growers are essential for continuous genetic improvement of the cowpea varieties with high yields and tolerance to biotic and abiotic stresses. Cowpea varieties recently recommended by the Government Department of Agriculture of Sri Lanka named "Waruni" and "Dhawala", short aged varieties were less preferred by the farmers in the rain fed area compared to the earlier released varieties such as "Arlington" and "Bombay Cowpea" (Hewavitharane et al., 2010). Development of farmer accepted varieties through a proper breeding methodology is essential to fulfil the actual needs of the cowpea farmers in the rain fed area of Sri Lanka. The knowledge on the relative efficiency of different breeding methods may help the plant breeders in selecting a better method to be adopted for a particular crop (Adnan et al., 2011). Therefore, evaluation of the efficiency of different breeding methods such as single seed descent (SSD) method, pedigree method (PM) and modified bulk method (MB) would be beneficial to strengthen the future breeding activities of cowpea. Hence, a study was conducted to compare three breeding methods based on the mean performance of selected traits of cowpea at F4, F5, F6 generations and estimating intergeneration correlation (r), narrow sense heritability and correlation between measured traits at each generation level.

\section{MATERIALS AND METHODS}

\section{Comparison of pedigree method, modified bulk method and single seed descent method}

A series of trials were designed to compare pedigree method (PM), modified bulk method (MB) and single seed descent (SSD) method using two cross combinations of from four distinct parents of cowpea to produce F4, F5 and F6 generations. The characteristics of the parent lines are shown in Table 1. The already derived populations of the F3 generation of two cowpea crosses namely CP19 x Waruni and CP20 x CP22 using pedigree, SSD and MB methods were used for the assessment. Six F3 populations with respect to two crosses and three breeding methods were maintained separately during 2011/12 Maha season.

Table 1. Characteristics of parental lines of the crosses

\begin{tabular}{ll}
\hline Parent & Characteristic \\
\hline CP 19 & $\begin{array}{l}\text { Indeterminate, large seeded, light brown seed, crowded seed shape, better } \\
\text { taste, low pod number, raceme position throughout canopy }\end{array}$ \\
Waruni & $\begin{array}{l}\text { Determinate, medium seeded, red colour seed, kidney seed shape, high pod } \\
\text { number, raceme position above canopy }\end{array}$ \\
CP 20 & $\begin{array}{l}\text { Indeterminate, small seeded, dark red seed, rhomboid seed shape, high pod } \\
\text { number, raceme position above canopy } \\
\text { Determinate, large seeded, white colour seed, ovoid seed shape, high pod } \\
\text { number, raseme position above canopy }\end{array}$ \\
\hline
\end{tabular}




\section{Pedigree method (PM)}

Two F3 populations each with 100 progeny lines from two crosses (one from each cross) were derived from 1000 plant populations of the F2 generation of respective crosses during the 2011/12 Maha season. For each of the two crosses, 100 separate progeny lines derived from the F3 generation by within and between lines selections were advanced to produce the F4 generation during 2012 Yala season. From the F4 generation, 100 plants were selected to produce 100 F5 progeny lines during the 2012/13 Maha season. Selection of 10 best lines was carried out at the F5 generation based on the preference ranking of breeders and farmers on visual observations for yield parameters, plant architecture and comparatively less pest and disease incidences.

\section{Single seed descent method (SSD)}

Two F3 SSD populations were derived from the F2 populations of the two crosses (one from each cross) by selecting one seed per plant from all the plants of respective $\mathrm{F} 2$ populations. Single seed descent F4 populations were derived from F3 populations of each of the two crosses. Each F4 plant was harvested and F5 generations were established as the progeny lines in both crosses. The F5 families or progeny lines were evaluated by the selected farmers and the breeders as in the pedigree method to select 10 best families or lines.

\section{Modified bulk method (Bulk)}

Two F3 bulk populations were derived by taking bulk samples from the F2 populations of the two crosses (one from each cross). The F4 bulk populations were established with the bulked seed samples from 5\% of selected plants of the F3 generation. Based on visual observations, the superior 5\% plants amounting to 100 were selected from the F4 generation. Hundred plants were established as lines in the F5 generation and were evaluated by selected farmers and breeders following the similar procedure as in pedigree and SSD methods to select 10 best lines.

\section{Comparison of three breeding methods at F6 generation}

The ten best lines selected from each of the three breeding method (30 lines in total) along with the parents of the relevant crosses and three standard checks were evaluated for their performance. Two separate experiments were conducted for each of the two crosses. Each experiment was laid out in a RCBD with three replicates, at the Grain Legumes and Oil Crops Research and Development Centre at Angunakolapellessa, Sri Lanka.

\section{Data recorded}

The plant height at maturity, number of peduncles per plant, number of pods per plant, number of seeds per pod, average pod length, hundred seed weight and seed yield per plant were recorded from randomly selected five plants of each progeny line in the F4 and F5 generations in PM, and from individual single plants of the F4 generation and five randomly selected plants from the progeny lines of F5 generation of SSD and from selected single plants of F4 generation and five randomly selected plants from the progeny lines of F5 of MB method. 
Days to $50 \%$ flowering, days to $50 \%$ maturity, plant height at maturity, number of peduncles per plant, number of pods per plant, number of seeds per pod, average pod length, hundred seed weight and seed yield were recorded from each line using a sample of randomly selected five plants from each plot of the replicated trials at the F6 generation. The seed yield of the total plot was also recorded.

\section{Comparison of breeding methods}

A separate ANOVA was computed for each experiment. The mean separation for each trait was done using DNMRT. Significance of the mean sum of squares of the breeding methods was tested using the mean sum of squares of lines within methods as the error term.

\section{Generation mean comparison, correlations among characteristics within generation and parent offspring regression}

For comparison among F3, F4 and F5 generation means within a pedigree, 80 random plants from each of the MB and SSD method and 80 random families (means) from the PM were assessed for seed yield and yield attributed characteristics. These plants, which were a part of the population and initially selected at the F3 generation, were advanced to the F4 and F5 generations. The means of recorded characteristics across generations within each of the three methods were calculated for each cross. Correlations of seed yield with other phenotypic characteristics were calculated for each generation within each breeding method.

Intergeneration or parent offspring regressions between the F4 and F5 generations and F5 and F6 generations for each of the recorded characteristics were estimated under pedigree method using the following Equation (Eq 1);

$$
\mathrm{r}_{\mathrm{xy}}=\mathrm{b}_{\mathrm{xy}} \frac{\boldsymbol{\sigma}_{x}}{\boldsymbol{\sigma}_{y}}
$$

where,

$\mathrm{b}_{\mathrm{xy}}=\frac{\text { covariance of } x y}{\sqrt{\text { variance of } x}}$

$\sigma_{\mathrm{x}}=$ Standard deviation of $\mathrm{x}$ (offspring)

$\sigma_{\mathrm{y}}=$ Standard deviation of $\mathrm{y}$ (parent)

The heritability values in narrow sense were calculated according to Smith and Kinman (1965; Eq 2).

Where, $\mathrm{h}^{2}=$ heritability in narrow sense.

$$
\mathrm{h}^{2}=\mathrm{b} / 2 \mathrm{r}_{\mathrm{xy}} \quad(02)
$$

$\mathrm{b}=$ regression coefficient

The correlations of seed yield with yield attributed characteristics within the F4, F5 and F6 generations were analyzed with Pearson correlation analysis using SPSS. 


\section{RESULTS AND DISCUSSION}

\section{Mean performance of seed yield and yield attributed characteristics of F4, F5 and F6 generations}

The means of seed yield and yield attributed characteristics of the F4, F5 and F6 generations of CP 19 x Waruni (Cross 1) and CP $20 \times$ CP 22 (Cross 2) from the three methods are presented in Tables 2 and Table 3, respectively, where the parameters varied across generations. In the F4 population of Cross 1 (Table 2), the PM recorded the highest mean values for plant height $(45.7 \mathrm{~cm})$ and pod length $(13.6 \mathrm{~cm})$. The SSD method recorded the highest number of pods per plant (13.7), peduncles per plant (9.5), average seed per pod (11.2) and seed yield per plant (14.9 g). The MB method recorded the highest value for hundred seed weight (13 g).

Table 2. Means of yield and yield attributed characteristics of F4, F5 and F6 generations of the cross 1 (CP $19 \times$ Waruni)

\begin{tabular}{lcccccc}
\hline \multirow{2}{*}{ Character } & & \multicolumn{5}{c}{ Selection method and parents* } \\
& Generation & PM & SSD & MB & CP 19 & Waruni \\
\hline Height $(\mathrm{cm})$ & F4 & 45.7 & 36.9 & 43.5 & 38.6 & 31.9 \\
& F5 & 38.8 & 39.1 & 62.4 & 59.4 & 52.2 \\
No of Pods/Plant & F6 & 40.8 & 40.2 & 41.9 & 44.1 & 42.2 \\
& F4 & 10.5 & 13.7 & 11.2 & 10 & 13.1 \\
No. of & F5 & 5.4 & 5.6 & 7.6 & 5.6 & 7.5 \\
Peduncles/Plant & F6 & 12.4 & 12.3 & 11.5 & 10.9 & 10.8 \\
& F4 & 9.3 & 9.5 & 7.9 & 8.6 & 9.3 \\
Average pod length (cm) & & & & & & \\
& F5 & 7.6 & 6.7 & 6.9 & 5.64 & 7.9 \\
Average seeds per pod & F6 & 8.4 & 8.5 & 7.2 & 8.11 & 7.2 \\
& F4 & 13.6 & 7.3 & 13.3 & 11.0 & 12.8 \\
100 seed weight(g) & F5 & 11.3 & 12.4 & 13.8 & 11.9 & 15.5 \\
& F6 & 15.1 & 14.9 & 15.9 & 14.1 & 15.9 \\
Seed yield per plant & F4 & 9.8 & 11.2 & 9.1 & 13.3 & 10.7 \\
(g) & F5 & 9.4 & 11.1 & 10.9 & 9 & 10.1 \\
& F6 & 12.9 & 11.9 & 13.8 & 14.3 & 12.4 \\
& F4 & 14.2 & 12.9 & 15.7 & 18.5 & 10.7 \\
Seed yield & F5 & 14.1 & 13.1 & 13.6 & 16.1 & 9.4 \\
(kg/ha) & F6 & 14.0 & 14.1 & 14.2 & 18.8 & 11.6 \\
*PM - Pedigree Method, SSD - Single Seed Decent Method, MB - Modified Bulk Method
\end{tabular}

In the Cross 2 (Table 3), the PM recorded the highest mean values for pods per plant (13.8), average pod length $(13.2 \mathrm{~cm})$, hundred seed weight $(10.74 \mathrm{~g})$ and seed yield per plant (15.0). The SSD method accounted for the highest values for plant height $(56.8 \mathrm{~cm})$, Peduncles per plant (8.4) and average seed per pod (11.9), modified bulk method recorded the highest mean value for 100 seed weight in the F4 generation. The mean performance of all three methods has reduced in the F5 population in the case of number of pods per plant and peduncles per plant, and pod length compared to the F4 population. The average seed per pod and hundred 
seed weight recorded comparable results in the F4 populations in both crosses. The mean values for the measured characteristics in the F6 generation were comparable among the breeding three methods but not with F4 and F5 generations within the respective methods.

Table 3. The means of yield and yield attributed characteristics of F4, F5 and F6 generations of the cross 2 (CP $20 \times$ CP 22)

\begin{tabular}{lcccccc}
\hline \multirow{2}{*}{ Character } & & \multicolumn{5}{c}{ Selection method and parents* } \\
\hline Height (cm) & Generation & PM & SSD & MB & CP 20 & CP 22 \\
& F4 & 41.8 & 56.8 & 42.5 & 44.5 & 39.1 \\
No of Pods/Plant & F5 & 49.1 & 45.6 & 62.5 & 47.4 & 46.9 \\
& F6 & 41.8 & 42.5 & 46.1 & 45.7 & 37.5 \\
No of & F4 & 13.8 & 11 & 11.1 & 12.1 & 11 \\
Peduncles/Plant & F5 & 11 & 7.6 & 8.7 & 7.6 & 6 \\
& F6 & 8.2 & 9.5 & 7.7 & 6.9 & 7.9 \\
& F4 & 7.7 & 8.4 & 6.3 & 7 & 6.4 \\
Average pod length (cm) & & & & & & \\
& F5 & 8.2 & 6.5 & 7.8 & 9.6 & 9.5 \\
Average seeds per pod & F6 & 5.1 & 5.6 & 4.7 & 4.6 & 6.7 \\
& F4 & 13.2 & 13.0 & 13.0 & 12.5 & 11.6 \\
100 seed weight(g) & F5 & 13.4 & 12.9 & 13.5 & 13.2 & 12.6 \\
& F6 & 14.3 & 14 & 13.7 & 13.5 & 14.5 \\
Seed yield per plant & F4 & 10 & 11.9 & 9.3 & 12.3 & 6.2 \\
(g) & F5 & 12.7 & 11.7 & 10.9 & 15.7 & 10.8 \\
& F6 & 14.0 & 13.2 & 13.2 & 15.4 & 10.3 \\
& F4 & 10.74 & 10.1 & 11.2 & 8 & 13.12 \\
Seed yield & F5 & 10.1 & 10.6 & 10.0 & 8.6 & 10.4 \\
(kg/ha) & F6 & 9.6 & 9.9 & 10.3 & 7.6 & 13.9 \\
$*$ PM- Pedigree Method, & SSD-Single Seed Decent Method, MB - Modified Bulk Method
\end{tabular}

\section{Comparison among breeding methods}

The mean sum of squares of the breeding methods, lines/methods and cv $\%$ for yield and yield related characteristics of Crosses 1 and 2 are presented in Table 4. The lines or the within method component was found to be significant $(\mathrm{P}<0.05)$ for all the characteristics except for the number of pods per plant, pod length and seed yield/ha in cross 1 and yield per plant in Cross 2. Breeding methods were found to be not significant when tested against lines/methods except for days to maturity $(\mathrm{p}<0.01)$ in Cross 1 and seeds per pod in both crosses $(\mathrm{p}<0.05)$. Therefore, in general, all three breeding methods are similarly effective in cowpea improvement. Ntare et al. (1984), using two crosses of cowpea early generation selection at F3 level, reported that the PM, SSD and MB were comparable in cowpea improvement. They also reported that the grain yields of lines derived by the SSD procedure were as good as those derived from early selection. However, Padi and Ehlers (2008) reported that the PM of breeding for grain yield in cowpea was ineffective. 
Table 4. Mean sums of squares of breeding methods, lines/methods and cv\% for yield and yield related characteristics of crosses 1 and 2.

\begin{tabular}{|c|c|c|c|c|c|c|}
\hline \multirow{2}{*}{ Characteristic } & \multicolumn{3}{|c|}{ Cross 1} & \multicolumn{3}{|c|}{ Cross 2} \\
\hline & $\begin{array}{l}\text { MS for } \\
\text { method }\end{array}$ & $\begin{array}{c}\text { MS for } \\
\text { lines/method }\end{array}$ & CV\% & $\begin{array}{l}\text { MS for } \\
\text { method }\end{array}$ & $\begin{array}{c}\text { MS for } \\
\text { lines/method }\end{array}$ & CV\% \\
\hline Days to flowering & 65.43 & $26.41^{* *}$ & 5.46 & 16.04 & $5.02 * *$ & 2.12 \\
\hline Days to maturity & $133.21 *$ & $31.6 * *$ & 4.64 & 23.011 & $14.21 * *$ & 3.55 \\
\hline Plant height $(\mathrm{cm})$ & 22.935 & $90.44 * *$ & 10.07 & 159.04 & $97.55^{* *}$ & 11.8 \\
\hline No of pods per plant & 8.5 & 12.47 & 25.7 & 26.39 & $16.82 * *$ & 28.18 \\
\hline No of peduncles per plant & 19.38 & $8.78^{*}$ & 25.33 & 6.78 & $4.67 *$ & 29.35 \\
\hline Pod length $(\mathrm{cm})$ & 9.148 & 4.635 & 7.67 & 0.52 & $3.67 * *$ & 6.94 \\
\hline No of seeds per pod & $27.085^{*}$ & $3.41 *$ & 9.41 & $7.41^{*}$ & 2.075 & 9.65 \\
\hline 100 seed weight $(\mathrm{g})$ & 0.356 & $12.909 * *$ & 10.52 & 3.033 & $10.05 * *$ & 14.77 \\
\hline Yield per plant (g) & 69.73 & $27.57 * *$ & 30 & 1.257 & 7.91 & 32.76 \\
\hline Yield kg/ha & 511034 & 221744.6 & 31.51 & 155028.4 & $78044.01 *$ & 30.93 \\
\hline
\end{tabular}

\section{Phenotypic correlation among seed yield and yield related characteristics}

The phenotypic correlation among yield per plant and other yield related characteristics in the F4, F5 and F6 generations are presented in Table 5. In the F4 generation, a significant positive correlation $(\mathrm{p}<0.01)$ was recorded between the No. of pods per plant and No, peduncles per plant in both Crosses in all three breeding methods. In the F5 generation, significant positive correlations $(\mathrm{p}<0.01)$ were recorded in all three methods between the yield per plant and pods per plant except in PM in the Cross 2. Siddique-Akbar and Gupta (1991) also recorded a significant positive correlation between the number pods per plant with the seed yield per plant in cowpea.

Table 5. Phenotypic correlations of seed yield per plant with yield related characteristics in F4, F5 and F6 generations

\begin{tabular}{cclccccccc}
\hline & & & & & & \\
\end{tabular}

**significant at $\mathrm{p}<0.01,{ }^{*}$ significant at $\mathrm{p}<0.05$ 


\section{Inter-generation correlation and narrow sense heritability}

The inter-generation correlation between the F4 and F5 generations and F5 and F6 generations and narrow sense heritability under each Cross are presented in Table 6. A significant positive inter generation correlations were observed between the F4 and F5 generations for plant height, number of pods per plant, pod length, hundred seed weight $(\mathrm{p}<0.01)$ and No of seed per pod $(\mathrm{p}<0.05)$ in Cross 1 . Hundred seed weight and the No of pods per plant $(\mathrm{p}<0.01)$ were positively correlated between the F4 and F5 generations in the Cross 2. The narrow sense heritability recordings for 100 seed weight of the Cross 1 was $56 \%$ and 58\% between F4 and F5 generations and F5 and F6 generations, respectively, while $44 \%$ and $97 \%$ were recorded for the same in Cross 2. The F5-F6 positive inter-generation correlations were observed for No of pods per plant, No of peduncles per plant and pod length in both Crosses. The narrow sense heritability of the No of pods per plant was $82 \%$ and $88 \%$ for Cross 1 and Cross 2, respectively, between the F4 and F5 generations and $61 \%$ and 51\% between F5 and F6 generations, respectively. Mathur (1995) reported a higher phenotypic and genotypic variation, heritability and expected genetic advance by studying the F2 population of cowpea and showed that the No of pods per plant was the major yield contributing characteristic. High heritability with high genetic advance has been reported for this characteristic in cowpea (Mehta and Zaveri 1999; Mathur, 1995). A study on segregating populations using limited genotypes have shown that number of pods per plant is highly variable (Rangaiah and Nehru, 1998).

Table 6. Inter generation correlation between F4 and F5 generations and F5 and F6 generations and narrow sense heritability $\left(h^{2}\right)$ under each cross

\begin{tabular}{|c|c|c|c|c|c|c|c|c|}
\hline \multirow[t]{3}{*}{ Characteristic } & \multicolumn{4}{|l|}{ Cross 1} & \multicolumn{4}{|l|}{ Cross 2} \\
\hline & \multicolumn{2}{|c|}{ F4-F5 } & \multicolumn{2}{|c|}{ F5-F6 } & \multicolumn{2}{|c|}{ F4-F5 } & \multicolumn{2}{|c|}{ F5-F6 } \\
\hline & $\mathbf{r}$ & $\begin{array}{r}\mathbf{h}^{2} \% \\
\text { (ns) }\end{array}$ & $\mathbf{r}$ & $\begin{array}{r}\mathbf{h}^{2} \% \\
(\mathrm{~ns})\end{array}$ & $\mathbf{r}$ & $\begin{array}{r}\mathbf{h}^{2} \% \\
\text { (ns) }\end{array}$ & $\mathbf{r}$ & $\begin{array}{r}\mathbf{h}^{2} \% \\
\text { (ns) }\end{array}$ \\
\hline Height $(\mathrm{cm})$ & $0.70 * *$ & 54 & $0.80 * *$ & 147 & 0.05 & 33 & -1.96 & 55 \\
\hline No.Pod/Plant & $0.40^{*}$ & 82 & 0.27 & 61 & $0.58 * *$ & 88 & 1.12 & 51 \\
\hline No. & -0.25 & 54 & 0.18 & 77 & -0.24 & 76 & 0.25 & 35 \\
\hline $\begin{array}{l}\text { Peduncles/plant } \\
\text { pod length } \\
(\mathrm{cm})\end{array}$ & $0.86 * *$ & 34 & 0.21 & 62 & 0.23 & 45 & 0.59 & 87 \\
\hline seed per pod & $0.34 *$ & 51 & $0.64 * *$ & 49 & -0.34 & 70 & -0.23 & 65 \\
\hline $\begin{array}{l}100 \text { seed } \\
\text { weight }(\mathrm{g})\end{array}$ & $0.49 * *$ & 56 & $0.86^{* *}$ & 58 & $0.63 * *$ & 44 & -0.07 & 97 \\
\hline $\begin{array}{l}\text { yield per plant } \\
\text { (g) }\end{array}$ & 0.005 & 71 & 2.8 & 12 & $0.88 * *$ & 48 & $0.38 * *$ & 62 \\
\hline
\end{tabular}

\section{CONCLUSIONS}

Pedigree, single seed descent and modified bulk breeding methods were found to be similar in performance and can equally be used for cowpea variety development. Based on the phenotypic correlations, inter-generation correlations and narrow sense heritability, the No of pods per plant and the hundred seed weight can be used as indirect selection criteria for high seed yield in the F4, F5 and F6 generations of cowpea. 


\section{ACKNOWLEDGEMENTS}

Authors wish to acknowledge Mr. B. N. Samaranayake, Research Officer and Mr. N.T. Prathapasinghe, Research Assistant of the Division of Grain Legume Breeding and all the Research Officers and technical staff, field assistants and labourers of Grain Legumes and Oil Crops Research and Development Centre (GLORDC) at Angunakoapelessa, Sri Lanka, for their enormous support throughout the research period.

\section{REFERENCES}

Adnan, K., Kondo, K. and Shashidhar, H.E. (2011). Comparative efficiency of pedigree, modified bulk and single seed descent breeding methods of selection for developing highyielding lines in rice (Oryza sativa L.) under aerobic condition. Electronic Journal of Plant Breeding, 2(2), 184 - 193.

Department of Agriculture. (2010). Pocket book of agricultural statistics, Socio Economic and Planning Center, Department of Agriculture, Peradeniya.

Hewavitharane, H.V.C., Warnakualsooriya, H.U. and Wajirakumara, G.B.S. (2010). Constraints to expansion of cowpea and mungbean under rain-fed farming in Anuradapuara district. Annals of the Sri Lanka Department of Agriculture. 12, 91 - 105.

Jayamanne, P.B. (1989). Strategies for the improvement of mung bean and cowpea production in the southern dry region of Sri Lanka. http//www.Govia .lk.

Mathur, R. (1995). Genetic variability and correlation studies in segregating generations of cowpea. Madras Agricultural Journal, 82, 150 - 152.

Mehta, N. and Zaveri, P.P. (1999) Genetic variability and association analysis in F5 generation resulted from 3 selection scheme in cowpea. Journal of Maharashtra Agricultural Universities, 23, 238 - 240.

Ntare, B.R., Akenowa, M.E., Redden, R.J. and Singh, B.B. (1984). The effectiveness of early generation (F3) yield testing and single seed descent procedures in two cowpea [Vigna unguiculata (L). Walp] crosses. Euphytica, 33, 539 - 547.

Padi, F.K. and Ehlers, J.D. (2008). Effectiveness of early selection in cowpea for grain yield and agronomic characteristics in semiarid West Africa. Crop Sci., 48, 533 - 540.

Rangaiah, S. and Nehru, S.D. (1998). Genetic variability correlation and path analysis in cowpea. Karnataka Journal of Agricultural Sciences, 11, 927 - 932.

Shiddique-Akbar and Gupta, S.N. (1991). Genotypic and phenotypic variability for seed yield and other traits in cowpea [Vigna unguiculata (L). Walp.]. International Journal of Tropical Agriculture, 9, 144 - 148.

Smith, J.D. and Kinman M.L. (1965). The use of parent offspring regression as an estimate of heritability. Crop Sci., 5, 595 - 596. 